\title{
Exploring The Role Of The Music Teacher From The Perspectives Of Parents And Teachers In West Malaysia
}

\author{
Kathryn Ang ${ }^{1} \&$ Albi Odendaal ${ }^{2}$ \\ MASARA, North-West University, Private Bag X6001, \\ Potchefstroom 2520, South Africa. \\ e-mail: Kathryn Ang ${ }^{1} / k_{\text {kathryn.lye@gmail.com }}$ \\ e-mail: Albi Odendaal ${ }^{2} /$ albi.odendaal@nwu.ac.za \\ Clorinda Panebianco \\ University of Pretoria, Room 3-14 Musaion, \\ Pretoria, South Africa. \\ e-mail: clorinda.panebianco@up.ac.za \\ DOI: https://doi.org/10.37134/mjm.vol8.3.2019
}

Published online: 15 August 2019

Cite this article (APA): Ang, K., Panebianco, C., \& Odendaal, A. (2019). Exploring the Role of the Music Teacher from the Perspectives of Parents and Teachers in West Malaysia. Malaysian Journal of Music, 8, 52-67. https://doi.org/10.37134/mjm.vol8.3.2019

\begin{abstract}
It is important for music teachers to reflect on the influence of their role during lessons. However, the roles of teachers, and expectations from both teachers and parents are often unclear, resulting in role confusion on both sides. The purpose of this collective case study is to describe and understand the expectations of both parents and teachers of the teacher's role in group music lessons for pre-school children in the Klang Valley ${ }^{1}$ of West Malaysia. Two semi-structured interviews were conducted with ten parents and three teachers of three group music classes for pre-school children. This study situates role theory as a conceptual framework to explore the perspectives of parents and teachers on the expected roles of teachers in group music lessons. Five broad categories of themes emerged, namely parentteacher perspectives on teachers' roles as multi-faceted professionals, authorities on music, entrepreneurs, mentors and communicators. A novel finding showed that teachers in West Malaysia play the role of entrepreneurs. Teachers are expected to be customer service providers, even babysitters, and are also expected to be generous with their time, which influences their entrepreneurship. The paper argues that role theory is a helpful tool in order to help teachers to understand how their roles play out in West Malaysia and how an understanding of their roles can help teachers to clarify the many expectations placed on them.
\end{abstract}

Keywords: group music lessons, parent-teacher perspectives, role of teachers, role theory, West Malaysia 


\section{Introduction}

Research suggests that teachers can play multiple roles in music education, such as: professional musician (Bouij, 2004), good presenter and facilitator (Ballantyne, Kerchner \& Aróstegui, 2012), assessor (Mills, 1991), contributor to the profession (Swanwick, 2008), self-evaluator and manager (Bukantaitė \& Kubiliūtè, 2015), role model (Isbell, 2015), and advocate and disciplinarian (Fischler, 2007). Therefore, the multiple roles that teachers can play in music education contribute to the complexity of the teacher's job.

The first author found during 36 years of experience in music education in the Klang Valley ${ }^{1}$ of West Malaysia that some parents expressed dissatisfaction with music teachers. These parents perceived teachers as not meeting their expectations (Biddle, 1979). Similarly, some teachers were also dissatisfied with parents, whom they perceived to have unrealistic expectations for their children. These parents may expect good results for their children, good value for money, low fees and excellent relationships with the teachers. Some parents can also be competitive in comparing their children's achievements with others, as they are status conscious; this inevitably creates undue tension for the teachers in trying to meet the parents' expectations for their children.

\section{Role Theory}

Taking into account all the roles that could be identified in music education may make the music teacher's task perplexing. Furthermore, parents and teachers might have different expectations of what the role of the teacher is, which may result in role confusion. This paper argues that role theory is a helpful tool to help teachers understand how their roles play out in West Malaysia, and how an understanding of their roles can help teachers to clarify the many expectations that are placed on them. Biddle (1979) maintains that there are two types of role expectations: personal and positional. He explains that, on the one hand, personal expectations are usually developed through first-hand experience with the person themselves and that they are context-specific. On the other hand, positional expectations are context-general and less defined, for example, the positional expectations for the behaviour of politicians and teachers.

Positional expectations, such as professional standards, and behaviours are described in the music education literature, but personal expectations are not typically emphasised. Turner (2002) employs the principles of functionality, representationality and tenability to describe how roles are reconstructed and to resolve role conflicts. Here the principle of functionality can be applied, where the teachers are expected to modify their roles by becoming partners in education with the families of their pupils, colleagues and the community by building and nurturing partnerships with them for greater effectiveness (Music Teachers National Association, 2004). The principle of representationality, Turner (2002) argues, means that roles "become vehicles for conveying certain images (representationality) and are framed and reframed in relation to what they are seen to represent" (p. 252). Representationality can clearly be seen in the literature where 
the teacher - represented as a guide - is not only expected positionally to be a capable leader, but is expected personally to have tact, resilience, a sense of humour and the ability to motivate others (Jorgensen, 2011). The principle of tenability means the teacher's role as a professional is subject to a balancing of costs and benefits, as the teacher strives to be a good instructor by being a constant learner in order to improve her own competences in teaching skills and knowledge, while being limited by her abilities and resources (Bukantaitė \& Kubiliūtè, 2015).

\section{Roles of Teachers in Music Education}

Although almost no research exists that addresses role theory within music education (the exceptions are: Cramer, Million \& Perreault, 2002; Miksza, 2007; Scheib, 2003), several emergent roles of teachers can be identified when the music education literature is read through the lens of role theory, such as, the roles of a professional musician and educator (Ballantyne et al., 2012, Bouij, 2004), partner in education (Bukantaitè \& Kubiliūtè, 2015) and role model (Ballantyne et al., 2012).

\section{Music Teachers as Professional Musicians and Educators}

The literature suggests that music teachers can be viewed as professional musicians who have a significant knowledge of music, are competent and skilled in performing on their instruments (Ballantyne et al., 2012; Bouij, 2004). Secondly, as educators, teachers are also seen as: good presenters who plan their pupils' courses of study and implement the lessons accordingly (Ballantyne et al., 2012); facilitators who have developed a range of resources, teaching approaches and strategies to motivate their pupils' learning (Ballantyne et al., 2012; Music Teachers National Association, 2004); assessors who have developed and validated measures to assess musical performance (McPherson, 1995; Mills, 1991); and guides (Cain, 1985; Jorgensen; 2011) who instruct, enable and display organisational skills, "tact, resilience, a sense of humour, and the ability to motivate others" (Jorgensen, 2011, p. 218). Moreover, as educators, teachers are also viewed as contributors to the teaching profession (Swanwick; 2008), self-evaluators and learners (Bukantaite \& Kubiliūtè, 2015; Swanwick, 2008). In a study evaluating teaching and learning in music education, Swanwick (2008) discovered that teachers who continued their professional development were able to be constructive contributors to their musical environment. Furthermore, teachers who continue their professional development also play the roles of self-evaluators, as well as learners and managers in continually assessing their personal teaching philosophy in enhancing their knowledge of current practices (Bukantaitè \& Kubiliūtè, 2015).

\section{Music Teachers as Partners in Education}

Additionally, the literature supports the notion of a teacher's role as a partner in education with the families of their pupils, colleagues and the community by building and nurturing partnerships with them (Bukantaite \& Kubiliūtè, 2015; Music Teachers National Association, 2004). As partners in education, Fischler (2007) described the teachers as playing the roles of advocate for their pupils and 
disciplinarian on behalf of the parents. Fischler (2007) explained the teacher's role as an advocate in representing the students by having discussions with members of the faculty, trustees and administration of the community school of the arts. She also added that teachers recognised their role as disciplinarians, but felt that new discipline systems could be developed so that the responsibility for maintaining discipline could be shared by the family, school, church and the media in order to free the teachers to focus on their teaching.

\section{Music Teachers as Role Models}

Finally, the literature suggests that music teachers play other roles such as a role model (Ballantyne et al., 2012; Creech \& Hallam, 2009; Isbell, 2015), nurturer (Ballantyne et al. 2012), and mentor (Dwyer, 2015; Leong, 2008). Creech (2009) describes a finding in her study where a teacher saw herself as a role model - both as performer and a person - for her pupils. Ballantyne et al. (2012) found that the pre-service teachers interviewed in the United States felt that they needed to think of various strategies in their teaching approaches in order to be nurturers of their pupils' musical abilities. Furthermore, teachers play the role of mentor by developing the relationships with pupils in order to make them more relaxed in their learning (Dwyer, 2015), as well as motivating and encouraging them during their early music making (Leong, 2008).

In summary, we have shown that teachers are expected to play multiple roles in this reading of the music education literature. However, this literature does not necessarily address the issues that are faced in Malaysia and therefore it is important to conduct a study on the way that teachers see themselves and how parents see teachers in Malaysia. Furthermore, this study investigated the teacher role within the group music class, a site that has not previously been investigated. The study was thus guided by the following research question: What are the expectations of the music teacher's role in group music lessons from the perspectives of both parents and teachers in West Malaysia?

\section{Methodology}

This collective case study (Stake, 1995) is part of a larger study ${ }^{2}$ that investigates parent-teacher relationships. This current article presents a cross-case analysis of parent and teacher' perspectives of teachers' roles within three cases. The three cases are pre-school group music classes within private settings in West Malaysia. The first case is an early childhood group music class for infants below 12 months of age; the second case is a group music class for toddlers with special needs; and the third case is a group music class for children between the ages of 5 and 6 years. Thirteen participants were selected by purposeful sampling comprising of the three teachers of the group music classes, and three parents of learners from two classes and four parents from one class. The basis of selection for the teachers was their experience with music education and group teaching, and their ability to communicate about their perspectives on teacher's roles. The parents, who were referred by the teachers, had varying levels of parental involvement with the 
teachers. In addition, it was important that these parents were able to describe their perspectives on teacher's roles openly. All participants who were invited to take part in the study were fully informed of the research before agreeing to complete letters of informed consent and assent.

Two semi-structured interviews, which were spaced about three to four months apart, were conducted with the ten parents and three teachers to explore the various ways that they describe the roles of teachers. During the interim between the first and second interviews, analysis of the first interviews took place in order to present the findings to the participants for member checking and further discussion (Creswell, 2013). In the second interview, participants were presented with stories crafted from a set of data that was gathered in a focus group interview with six music teachers who described their experiences, both positive and negative, of parent-teacher relationships. The teachers have extensive experience of at least 10 years and are qualified by external examination boards such as the Trinity College London and London College of Music. They teach in a variety of places in the Klang Valley and some of them work together. They give piano instruction in a one-on-one setting. In addition, two of them have experience teaching aural skills and theory in a group setting.

While the first semi-structured interview inquired about the participants' understandings and experiences of a teacher's roles, the second made use of four factional stories as a means of eliciting responses on covert role expectations from both parents and teachers. Kallio (2015) explains that such 'factional stories' are constructed from a diverse range of previously collected data, analyses and fictive elements, which combine both the research participants' and the researcher's voices. The factional stories were used in both group and one-on-one settings. One of the stories described a positive experience a teacher had with a parent, where both parties were willing to make a great effort in order for the pupil to continue having lessons with the teacher. This was done in order to preserve the good working relationship all three parties had with each other. The remaining three stories related to tense situations, where a parent was in direct conflict with the teacher for not answering her phone call, another where the parent was insisting that her child take an examination at a higher grade than was appropriate, and where a parent was unhappy with the teacher for not wanting to carry on teaching her child.

Data collected from the 24 interviews were transcribed verbatim, as well as analysed and coded in Atlas.ti. The first author carried out the process of coding in consultation with both second and third authors. Coding was a collaborative process that involved regular interaction between the authors with the first author doing the majority of the coding. Values coding was used as it reflects "a participant's values, attitudes and beliefs, representing his or her perspectives or worldview" (Saldaña, 2016 , p. 131). The twenty codes that were identified fell into five categories, as stated in the results. To improve the validity of this study, the various comments garnered from the participants in the member checking (Creswell, 2013) helped the first author to have a better understanding of the reliability of the analysis. To protect the participants' identities, we gave pseudonyms beginning with ' $\mathrm{T}$ ' to the teachers (Teresa, Tina and Tricia) and pseudonyms beginning with ' $\mathrm{P}$ ' to the parents (Paloma, Pamela, Pang/Pei Ting, ${ }^{3}$ Patricia, Peggy, Peng Li, Phoebe, Prisha 
and Pui Li).

\section{Results}

Results are presented based on the responses of the parents and teachers to the question on the nature of teachers' roles in the context of group music lessons in the Klang Valley of West Malaysia. Five broad categories of themes emerged, namely parent-teacher perspectives on teachers' roles as multi-faceted professionals, authorities on music, entrepreneurs, mentors and communicators. The discussion that follows explores various components of each theme and highlights parents' and teachers' perspectives on these roles. Although this study was focused on group lessons only, the responses included many references to one-on-one lessons by teachers who recounted their personal experiences as well as by parents who were responding to the factional stories, which enriched the context of the study, and so we decided to include them.

\section{Music Teacher as a Multi-Faceted Professional}

Both teachers and parents shared the perspective that the teacher should display the attributes of being a multi-faceted professional which includes a good presenter and facilitator, and be able to educate parents to enhance children's wellbeing and learning outcomes. Parents also spoke of the importance of teachers managing transitions for their children.

There were various opinions of what being a professional means to both teachers and parents. Parents' and teachers' views of teacher's professionalism included teachers behaving without prejudice and creating an environment conducive to learning for the children. Tina strongly believed that it was professional for everyone to be treated fairly and without prejudice. She explained that, as she has 300 students in her centre, it is very important for her to be consistent in her policies. Prisha was happy with the teacher of the group music class her daughter attends who said that "every kid has [her] own style". Prisha attributes this statement to her perception that the teacher does not show prejudice in class and therefore would not compare one child with another.

In responding to a factional story where the parent took care of the teacher's baby while she taught her daughter, Tina said "I also feel that it is very distracting with the [baby] around [while] the teacher is teaching". Tina felt that it was not professional of the teacher to have the baby in the room while teaching, as it was important to maintain an environment conducive to effective teaching. Furthermore, parents also emphasised that the teachers' professionalism was seen in their emotionally stable temperaments. Phoebe recounted an instance when a teacher who was being shouted at by the parent displayed a high level of professionalism and self-control by not retaliating.

Teresa felt strongly that in order to be a good presenter, a teacher should explain an activity before doing it. One of the parents in Teresa's group music class, Pang, valued her clear instructions during the class because he found that "the explanations will help us see why the programme is structured in such a way". In 
addition, parents showed a clear appreciation of teachers who were adaptable in their teaching. Patricia appreciated the teacher for adapting the programme to improve her special needs child's "gross motor development". In addition, parents also enthused over teachers who were patient and passionate about teaching the children. Patricia elaborated that the teacher of her special needs child was "very passionate" about the class and would "[go] at the children's pace".

Teachers stressed the importance of coordinating, communicating and connecting with parents in order to be effective facilitators. Tina makes it a point to coordinate with the parents by informing them of the child's progress and assigned work after each class. She would also send a text message to any parent who was not at the debriefing session. However, Tricia had a different approach as she left it to the parents to decide whether or not to attend the class in order to know what was going on. Teresa stressed the importance of seeing parents 'face to face' in order to bond well or make a connection with them.

In discussing whether the responsibility of the learning outcomes of a child should fall on the pupil, parent or teacher, Pui Li viewed teachers only as facilitators. She added that "it will be the responsibility of the child mostly because he is the one who has to learn for himself." In contrast, Pang felt that the learning outcome of the child was the teacher's responsibility because "teachers are trained to teach". However, Phoebe presented a more balanced viewpoint as she felt both teachers and parents had different roles to play. Her view as that "on one hand, the teacher should help [the children], and on the other hand, the parents should spend some time to understand their [children's] music".

In playing the role of educating parents, Teresa felt that in her group music classes she was not only teaching the child but the parents as well. Parents also felt that they were learning together with their children in the group music classes. Prisha was excited by the teacher's approach to teaching, as she would regularly update the parents on "how to play the [piece]" in a really detailed manner. Furthermore, teachers discussed the importance of managing parents as part of their attempts to educate them. Tricia had to educate a parent on the practice time necessary for her child to be ready for an examination, as the parent was uninformed and thought that taking the examination did not require that kind of effort. Tina stressed that it was vital for parents to have a close relationship with the teachers in order to be educated in areas such as managing their expectations of their children. She also stated that she would help the parents in their time management by saying "you cannot be busy all the time and [have] no time to guide the child. You have to make it [a] point - for the benefit of the child's learning".

A further role was for teachers to manage transitions for the children when they change from one class to another. Pei Ting was pleased that her children's teacher would "normally [have] this transition period. So, she will [give guidance to] the young teachers in the class" in order to help the children and parents adapt to the new teacher.

There was thus a range of positional and personal expectations from both parents and teachers on teachers performing the role of a multi-faceted professional. For the most part, parents were satisfied with the teacher's professionalism in being fair and not prejudiced in dealing with the children, as well as in maintaining high 
levels of self-control and emotional stability. In addition, parents felt that the teachers were fulfilling their role as good presenters functionally and meeting both positional and personal expectations by giving clear explanations and adapting programmes to meet the needs of the children, and by being patient and passionate about teaching the children. Teachers felt that they were meeting the parents' positional expectations by performing the role of a facilitator, which required teachers to coordinate, communicate and connect with the parents. However, parents had different positional expectations on the teacher's role as a facilitator, as they were more concerned about whether the teacher was merely a facilitator or whether the responsibility for the child's learning outcomes should fall solely on the teacher. In addition, teachers felt that they were meeting the parents' positional expectations by educating the parents along with their child during the group music lessons. Parents expressed a similar sentiment that their expectations were being met as they were learning together with their children during the classes. Furthermore, teachers also felt that they were educating the parents by helping them in their time management in order to find the time to guide their children. One parent had a positive experience when a teacher managed the transition for both the children and the parents when there was a need to change classes. It is therefore clear that there is a range of perspectives within each role and that the roles are always being negotiated.

\section{Music Teacher as an Authority on Music Education}

Teresa stressed the importance of having the trust and respect of the parents while teaching their children. With these values in place, she felt empowered to teach. In discussing how to manage a demanding parent, she added "I don't want any parent to tell me what to do, because ... [I will] lose the respect of other parents [if]I give in to the demands of the parent". Teresa felt that it was necessary to assert her authority in the area of teaching and stated that "as a teacher I must remember that I should not try to please everyone. I think it is all for the good of the child".

Tina strongly felt that she had to be a gatekeeper in removing any disruptive influence from her group classes who was affecting the other children. She recounted an experience of having a child in her class who was disrupting the lesson: "[I told the parent that her child] is interrupting other children. So, I said maybe he is not ready for [group] music [lessons] yet”. Similarly, Teresa recounted an incident of disciplining a rebellious child in her group music class whom she had to take out of the room to reprimand in the presence of his parent.

Patricia expressed negative sentiments about the parent in one of the factional stories who overstepped the mark by taking over the role of a pacesetter from the teacher. In her view, it was the teacher who should have decided whether it was the right time for the child to advance to the next level, "because the teacher [has] experience, ... and she knows the child because she has been teaching the child".

Teachers provided more perspectives than parents on their role as a music education authority. When discussing empowerment in teaching, teachers stressed that they needed the trust and respect of the parents in order to meet the parents' 
positional expectations and function well in this role. They also felt that they were performing their role as gate-keeper by exercising discipline and keeping disruptive influences out of their classes. Teachers also emphasised the importance of asserting their authority, especially in being a pacesetter for their pupils. Teachers were aware of the challenges that some parents would pose by insisting on a quicker timeline, but the teachers felt strongly that they were performing their role as an authority on the educational process by asserting their timeline for the pupil's lessons. Teachers were also playing the role of an assessor as the pace of work would depend on their assessment of how the child was progressing in the classes. Parents also agreed that the teachers should be supported in their roles as assessor and the relevant person who can authoritatively assert the appropriate pace of progress for the child, because they were in the best position to make the right decision for the children.

\section{Music Teacher as an Entrepreneur}

Teachers said that as entrepreneurs they had to play the role of a customer service provider in order to retain the parents as customers. Otherwise, they would lose the students and this would impact on the business aspect of their teaching. Tricia felt that she had to be a 'genie', performing 'superhuman' acts to meet the expectations of unreasonable parents. Teresa commented on the behaviour of the parent in a factional story who was angry with the teacher because she had a bad dream about her. She felt that the dream may have been rooted in an existing bad relationship between the parent and the teacher. So it was in the interest of the teacher to adopt the approach of a customer service provider to find out what was truly ailing the parent. Teresa emphasised the importance of being polite and reassuring towards the parent by talking 'slower and softer' and using the 'three magic words: please, thank you and sorry' to appease an angry parent. Patricia shared a similar opinion that "the teacher could be humble first to [take] the first step to contact the parent and to start the reconciliation [process]".

Teresa bemoaned that fact that certain parents regarded the teachers merely as babysitters. Tricia added that these parents would often turn up late, expect her to give the full duration of the lesson and also leave their child with her to babysit after the class. Pei Ting described that some parents pay "so that [the teacher] can take care of [their] son" while they do other things. Therefore, these parents clearly viewed the teachers as babysitters. But in general parents expected teachers to play the role of a customer service provider by being problem solvers. Pamela and Patricia who are parents of children in the classes for babies and toddlers with special needs, took the initiative to meet up with the teachers, usually after a class, to get the teacher's advice on the problems their children were facing.

Peng Li commented that some teachers are over-calculating with the class time. She added "once it [reaches] half an hour, the teacher will leave". Peng Li was of the opinion that "If the teacher only does it for the sake of money ... that's not good". It appears that parents expect teachers to be generous with their time. Giving a lesson according to the stipulated time was considered as the teacher being overcalculating. In addition, Pui Li felt that the parent in the factional story in which the 
mother expected the teacher to rush and prepare her child for an examination by giving him extra lessons for free was expecting the teacher to be over-generous with her time. She felt that the teacher should not be compelled to give the lessons for free, because the mother had not done her part in supervising and guiding her child.

Therefore, teachers and parents were of the opinion that in playing the role of an entrepreneur, teachers were perceived as customer service providers in diplomatically handling some demanding parents who had high positional expectations of them. Cheong (2018) describes entrepreneurship as "small business ownership which implies quality of innovation, initiative and creativity in establishing a new venture" (p. 78) with the aim of making a profit. From an entrepreneurial perspective, the benefit of teachers meeting these parents' personal expectations is to retain the parents as customers and this would have a positive impact on the business aspect of their teaching. In addition, certain parents seemingly took advantage of the teachers, who were expected to play the role of babysitter as the parents arrived very much later than the appointed time to collect their children from the music centre. Furthermore, parents expressed negative sentiments about teachers whom they felt were over-calculating because they taught the lesson strictly for the stipulated time. Therefore, it appeared that in some cases the teachers were not meeting the parents' personal expectations of the teacher, which were that teachers should be very generous with their time by extending the lesson time and even giving free lessons.

\section{Music Teacher as a Mentor}

In the role of mentor, teachers saw themselves as an advisor, encourager and counsellor for their pupils as well as their pupils' parents. Tina felt strongly about the value of being an advisor and stated that she would help plan a time-table for a child who apparently had no time to practise. She would also involve the parents in the planning and advise them on how to supervise the child at home. Tricia discourages parents from forcing their children to practise, but asks them to encourage their children instead. She would also counsel parents who were "stressed ... if their kids didn't want to behave that day" by offering them a listening ear.

In playing the role of a nurturer, teachers held the view that they had to befriend their pupils and also protect them. Teresa felt that "once a child is handed to you, you are responsible till the child grows up or the child leaves you". Tricia and Teresa believed in befriending their pupils and their parents. Tricia recounted an experience where she took the initiative to visit her pupil who was sick in hospital. She also prayed for the child to recover and the parents and the child were happy to see her. Furthermore, Tina believed in treating her pupils as family members. She declared that she loved her pupils and would nurture, guide and develop them.

Parents viewed the teacher as a role model who would be instrumental in building their children's character. Prisha stated that parents who did not feel there was any benefit in having a close relationship with their children's teacher "[did not] know how important the teachers are in their kid's life because ... teachers also 
are very good role models for their [kids]". In addition, Patricia was particular about the faith embraced by the teacher by saying "that if a teacher is a Christian she would also try to instil the same kind of values and have grace and be merciful [and] loving".

Parents stressed the importance of teachers developing good relationships with their children. Peggy lauded the efforts of her child's teacher by stating that "her interaction is amazing - how she is able to interact with the kids at the same time as with the parents". Paloma was enthusiastic about teachers having good relationships with the children, as she felt it would encourage the children to learn and be motivated to continue in the teacher's class.

Teachers felt that they had met the parents' personal expectations in their role as a mentor for their pupils in the areas of being an advisor and nurturer, when they acted as encourager, counsellor and protector. In addition, parents expressed satisfaction that the teachers had met their personal expectations by being a role model in building their children's character, and by developing relationships with their children in having motivational interactions with them.

\section{Music Teacher as Communicator}

As stated in the perspectives of teachers as a mentor, the participants expressed the view that the teachers of the group music classes had good communication skills and believed in befriending their pupils and their parents. However, parents recounted experiences with other teachers who had not met their personal expectations in their role as communicator. Peggy felt that teachers have to be approachable in order for parents to be more involved in their children's education. She added that this would discourage 'helicopter' parenting, where the parent merely hovers around but does not communicate with the teacher or the children on their progress in learning. She concluded by stating "that is why it's important to have that three-way communication with the kid, the teacher and the parent".

Prisha stressed that teachers should maintain a relationship with parents as they have a very important role to play in keeping the parents informed about what is happening to the child. In responding to a factional story where the teacher informed the parent by a text message that she would be transferring her child to a group class from her one-on-one setting, Pui Li and Pei Ting felt that the teacher should have spoken to the parent "face to face" in order to avoid any misunderstanding. Pui Li added that it was vital to have "open communication". Clearly, this situation pointed to a weakness in the relationship between the parent and the teacher.

Parents valued having teachers as friends in order to communicate freely with them. Prisha regards her child's teacher firstly as a teacher and secondly as a friend. Pamela expressed a similar sentiment in thinking of her child's teacher as a friend. She added that she would express her appreciation to her on special occasions such as teachers' day and Christmas day. Patricia commented that in the factional story where the mother did whatever it took for her daughter to continue lessons with the teacher, the basis of her decision was that the mother and the teacher had become friends and were willing to help each other out. Paloma valued 
having her child's teacher as a friend as it would improve understanding and they would be able to 'discuss every problem together'. She strongly believed that this would be beneficial for her child.

There was a range of responses from the parents on the teachers' role as communicator. Some parents found that teachers who were less approachable did not meet their expectations as communicators. Furthermore, parents felt that some teachers did not make a point of keeping the parents informed of their children's progress. Parents expressed dissatisfaction with teachers who did not make the effort to have a 'face-to-face' meeting with the parents on important issues as they did not meet their personal expectations. For some parents, building a friendship with the teacher was the basis of the teacher performing her role as communicator. Some teachers in the group music classes had clearly built friendships with the parents, but some did not, as stated by the parents.

\section{Discussion}

The results of this collective case study draw special attention to the expectations participants have of teachers' roles in group music lessons - as multi-faceted professionals, authorities on music, entrepreneurs, mentors and communicators. It should be emphasized that these roles are not fixed and pre-determined role categories, but rather that they are negotiated and dependent on interaction between the role players (Turner, 2002). As such these labels are not normative but descriptive and present a picture of a fluid reality. There may be interpersonal conflict between the teachers and parents because they have different perceptions of the roles teachers play. Furthermore, there may even be an aspect of intrapersonal role conflict for the teacher in trying to strike a fine balance between playing the various roles. For example, in a literature review on musician/performer role conflicts, Miksza (2007) discusses that pre-service music teachers may experience role conflicts in trying to understand their identity in playing both roles.

We will now consider these results through the theoretical lens of role theory, which applies the principles of functionality, representationality and tenability in understanding role differentiation (Turner, 2002). In keeping with the principle of functionality, there is a clear understanding of responsibilities and collaboration between parties, and because of this collaboration, "roles are constantly modified for greater apparent effectiveness" (Turner, 2002, p. 252). For example, teachers adapted their roles as professionals and mentors (see also Ballantyne et al., 2012; Dwyer, 2015; Leong, 2008) for better outcomes in teaching. As professionals, teachers felt they were regularly modifying their role as good presenters in order to be more effective by incorporating the education of parents into the planning and execution of the group music lessons. This was shown in the explanations that teachers gave prior to an activity during the lesson to help the parents understand why the programme was structured in that particular way. Furthermore, parents showed a clear appreciation of teachers who were flexible in their teaching, as the teachers were willing to modify their role as good presenters by adapting their programmes to suit the needs of the children, especially pertaining 
to the challenges faced by children with special needs. In addition, a teacher went beyond the expectations of a parent by modifying her role as a professional to include managing the transitions for the children when they changed from one class to another. This led to smooth and effective transitions for both the parents and the children. As mentor, teachers were always flexible in their role as an advisor in guiding parents on managing their children's time-tables and supervision of practice. The guidance from the teachers led to parents being more effective in making music part of their children's lives at home. Teachers also went beyond parents' personal expectations as mentors by modifying their role as nurturer in being willing to befriend their pupils, protect and also pray for them. As a result, both the parents and their children were comfortable with these teachers.

However, parents also felt that some teachers did not fully meet their role expectations as communicators (see also Lueder, 2000; Miretzky, 2004), because there was insufficient interaction between the teachers and the parents to build a friendship. As there seems to be a lack of clarity on what the role represents, this perspective can be viewed in terms of the principle of representationality, where roles "become vehicles for conveying certain images (representationality) and are framed and reframed in relation to what they are seen to represent" (Turner, 2002, p. 252). It was found that some parents did not feel comfortable about approaching certain teachers, possibly because of the image they had of these teachers. Therefore, teachers need to be aware of the image they represent to the parents and the resulting tensions that may occur between both parties. In keeping with the principle of representationality, teachers could reframe the image they project by initiating open conversations with the parents and being more interactive with them.

From the perspective of tenability, Turner (2002) explains that "roles are subject to continuous tension to supply a tenable balance of benefits to costs for role incumbents, limited by the power and resources of those incumbents" (2002, p. 252). There was a marked difference in the way that the participants viewed costs and benefits when they discussed group teaching compared with when they discussed one-on-one teaching. This could be a result of parents being more focused in the group context on the children's wellbeing and learning outcomes, and less concerned with the costs, which is a more prominent issue in the one-on-one context. Some of the interactions and negotiations between parents and teachers in the one-on-one context revolved specifically around payment and parents' personal expectations of the teacher. In particular, some parents were dissatisfied with teachers who taught the lessons strictly within the stipulated time and who did not give free lessons. These parents described the teachers as being calculating. This became a source of tension and a cost for the teachers in terms of financial, emotional and opportunity costs, if they tried to satisfy the expectations of the parents. In addition, certain parents continued to seek further role benefits by having personal expectations of the teacher as a babysitter. Consequently, the parents regularly arrived very much later than the appointed time to collect their children from the music centre. In keeping with the principle of tenability, teachers' roles are also subject to continuous tension as they try to accommodate the behaviour of the parents at great cost to their image, personal schedules and loss of time for other teaching. From an entrepreneurial perspective, the benefit of teachers meeting these 
parents' personal expectations is to retain the parents as customers, but the teachers were aware that parents continued to seek for additional benefits such as convenience and highly accommodating responses from teachers.

\section{Conclusions}

This paper contributes to the studies on teachers' roles in music education by showing that teachers are described by both teachers and parents as multi-faceted professionals, authorities on music education, entrepreneurs, mentors and communicators. This study makes a contribution to research on music education in West Malaysia by suggesting that teachers' roles in their pupils' musical learning and development need to be reconceptualised. The results of this research seem to indicate the need for a better understanding of the expectations of teachers' roles in group music lessons from both parents and teachers. Teachers could work towards understanding the positional and personal expectations of parents as that would help them to clarify these roles. In applying Turner's (2002) principles of functionality, representationality and tenability in role differentiation, the teachers could modify their roles for 'greater apparent effectiveness' (p. 252). Teachers could become more aware of the image they represent to parents, and could frame or reframe their roles until they meet the expectations of those around them. Teachers could also play their role of balancing costs and benefits in relation to the parents in a positive way without compromising their role as professionals. This may be due to the role conflict that teachers may experience within themselves. The practical implications of these findings are that teachers should continue fulfilling their role as a multifaceted professional by being good presenters and facilitators, and extending the education to include the parents; but teachers could also help the parents understand that the responsibility for the learning outcomes of the children should be shared among all three parties - the teacher, parent and the pupil. Teachers who have difficulty communicating with parents could improve on their role as communicator by being more aware of the image they are projecting to the parents, which may be a source of tension between them. Teachers could regard the parents as partners in education and encourage them to work alongside their children with a common goal of improving their children's wellbeing and learning. Finally, teachers who are facing problems with some demanding parents could help parents manage their expectations of teachers, such as desiring more time than that stipulated for the lessons, or free lessons and extra child-care services after the lessons by "establishing operational and financial policies" (Music Teachers National Association, 2004, p. 1) from the beginning of the lessons. Teachers could also adopt a more diplomatic approach by using words like 'please, thank you and sorry' spoken in slower and softer tones when dealing with demanding parents.

We believe that this research will encourage more open conversations between teachers and parents in order to help teachers to understand the expectations parents have of their roles. Teachers could also benefit from this study through developing a more focused understanding of these expected teachers' roles, which would help them in their interactions and negotiations with the parents of their pupils in music lessons. 


\section{Endnotes}

1 The Klang Valley is an area around Kuala Lumpur in West Malaysia. It includes the neighbouring cities and towns in the state of Selangor.

${ }^{2}$ The larger study is a doctoral thesis that investigates parent-teacher relationships in group music lessons. This article addresses the expected roles of teachers in group music lessons, while another (under review) addresses the expected roles of parents. In a third article, Ang, Panebianco \& Odendaal (2019) discuss parent-teacher partnerships in group music lessons.

3 This husband and wife couple took turns in answering questions during the interview because they were caring for their baby.

\section{References}

Ang, K., Panebianco, C., \& Odendaal, A. (2019). Parent-teacher partnerships in group music lessons: A collective case study. British Journal of Music Education. https://doi.org/10.1017/S026505171900024X

Ballantyne, J., Kerchner, J. L., \& Aróstegui, J. L. (2012). Developing music teacher identities: An international multi-site study. International Journal of Music Education, 30(3), 211-226. https://doi.org/10.1177/0255761411433720

Biddle, B. J. (1979). Role theory: Expectations, identities, and behaviors. New York, NY: Academic Press.

Bouij, C. (2004). Two theoretical perspectives on the socialization of music teachers. Action, Criticism, and Theory for Music Education, 3(3), 1-14. http://act.maygroup.org/articles/Bouij3_3.pdf

Bukantaite, D., \& Kubiliūte, M. (2015). Factors which motivate music teachers' training in their working environment. Applied Research in Health \& Social Sciences: Interface \& Interaction / Sveikatos Ir Socialiniu Mokslu Taikomieji Tyrimai: Sandura Ir Saveika, 12(1), 24-32. https://doi.org/10.1515/arhss-2015-0004

Cain, T. (1985). Teacher as guide: The teacher's role in the secondary school music lesson. British Journal of Music Education, 2(1), 5-18. https://doi.org/10.1017/S0265051700004575

Cheong, K. W. (2018). Understanding the pull motivations of Malaysian women music teachers as music entrepreneurs. Malaysian Journal of Music, 7, 78-99.

Cramer, K. M., Million, E., \& Perreault, L. A. (2002). Perceptions of musicians: Gender stereotypes and social role theory'. Psychology of Music 30 (2), 164-74. https://doi.org/10.1177/0305735602302003

Creech, A. (2009). Teacher-pupil-parent triads: A typology of interpersonal interaction in the context of learning a musical instrument. Musicae Scientiae, 13(2), 387-413. https://doi.org /10.1177/102986490901300208

Creech, A., \& Hallam, S. (2009). Interaction in instrumental learning: The influence of interpersonal dynamics on parents. International Journal of Music Education, 27(2), 94-106. https://doi.org/10.1177/0255761409102318

Creswell, J. W. (2013). Qualitative Inquiry and Research Design: Choosing Among Five Approaches (3rd ed.). Thousand Oaks: SAGE Publications, Inc.

Dwyer, R. (2015). Unpacking the habitus: Exploring a music teacher's values, beliefs and practices. Research Studies in Music Education, 37(1), 93-106. https://doi.org/10.1177/1321103X15589260

Fischler, G. L. (2007). Actual and ideal roles of music teachers in community schools of the arts pertaining to community, school, and the profession (Doctoral dissertation). Retrieved from http://hdl.handle.net/10150/195791 
Isbell, D. S. (2015). The socialization of music teachers. UPDATE: Applications of Research in Music Education, 34(1), 5-12. https://doi.org/10.1177/8755123314547912

Jorgensen, E. R. (2011). Pictures of Music Education. Bloomington: Indiana University Press.

Kallio, A. A. (2015). Factional stories: Creating a methodological space for collaborative reflection and inquiry in music education research. Research Studies in Music Education, 37(1), 3-20. https://doi.org/10.1177/1321103X15589261

Leong, K. Y. G. (2008). Love it, love it not: Parental attitudes regarding children's music learning in Kuala Lumpur (Bachelor's dissertation). University of Sydney. Retrieved from https://ses.library.usyd.edu.au/handle/2123/3993

McPherson, G. E. (1995). The assessment of musical performance: Development and validation of five new measures. Psychology of Music, 23(2), 142-161. https://doi.org/10.1177/0305735695232003

Miksza, P. (2007). Musician/performer role conflict. In J. W. Scheib (Ed.), Roles, identity, socialization, and conflict: The transition from music student to music teacher (a literature review) (44-49). Society for Music Teacher Education (SMTE).

Mills, J. (1991). Assessing musical performance musically. Educational Studies 17(2), 173 81. https://doi.org/10.1080/0305569910170206.

Music Teachers National Association. (2004). 'What a Nationally Certified Teacher of Music (NCTM) Should Know and Be Able to Do', (2004). Retrieved October 26, 2018, from https://certification.mtna.org/Certification/Explore_Certification/Standards/Certific ation/Explore/Standards.aspx?hkey=67dc5659-7120-4ffc-bf50-c8a665a4ee3b.

Saldaña, J. (2016). The coding manual for qualitative researchers. London: SAGE Publications Limited.

Scheib, J. W. (2003). Role stress in the professional life of the school music teacher: A collective case study. Journal of Research in Music Education 51(2) 124-136. https://doi.org/10.2307/3345846

Stake, R. E. (1995). The art of case study research. Thousand Oaks: SAGE.

Swanwick, K. (2008). The 'good-enough' music teacher. British Journal of Music Education, 25(1), 9-22. https://doi.org/10.1017/S0265051707007693

Turner, R. H. (2002). Role theory. In J.H. Turner (Ed.), Handbook of Sociological Theory (pp. 233-254). New York, NY: Plenum Publishers.

\section{Biography}

Kathryn Ang is a music educator and pianist based in West Malaysia. She is currently working on a $\mathrm{PhD}$ in music at the North-West University in South Africa. Her research interests include music education, piano didactics and the performing arts.

Clorinda Panebianco is a senior lecturer in the Department of Music at the University of Pretoria, Pretoria, South Africa. Her research interests lie in health and wellness issues in the performing artists, as well as music and wellbeing in society.

Albi Odendaal is a senior lecturer in the School of Music at the North-West University in South Africa. His research interests include psychology of music, music education and higher education. 